\title{
Üniversite Öğrencilerinde Dışadönüiklük, Sosyal Ağları Kullanma Sıklığı ve Cinsiyetin Problemli Sosyal A ̆ Kullanımına Etkisinin İncelenmesi
}

\section{Examining the Effect of Extraversion, Frequency of Social Networks Use, and Gender on Problematic Use of Social Network among University Students}

\author{
Ahmet Kesici ${ }^{1}[$
}

'Dr., Siirt Milli Eğitim Müdürlüğü, Siirt, Türkiye

ORCID: A.K. 0000-0003-1830-497X

Sorumlu yazar/Corresponding author: Ahmet Kesici,

Siirt Milli Eğitim Müdürlüğü, Siirt, Türkiye E-posta/E-mail: ahmetkesici@yahoo.com

Başvuru/Submitted: 14.08 .2018 Revizyon Talebi/Revision Requested: 23.10.2018

Son Revizyon/Last Revision Received: 10.03.2019

Kabul/Accepted: 19.03 .2019

Online Yayın/Published Online: 06.05.2019

Atıf/Citation: Kesici, A. (2019). Üniversite öğrencilerinde dışadönüklük, sosyal ağları kullanma sıklığı ve cinsiyetin problemli sosyal ağ kullanımına etkisinin incelenmesi. Psikoloji Çalışmaları - Studies in Psychology, 39(1): 23-44.

https://doi.org/10.26650/SP2018-0013
ÖZ

Problemli sosyal ağ kullanımı, kişinin sosyal ağlara katılma güdüsüne karşı kendini kontrol edememesi ile ilgili bir sorundur. Bu sorun, kişide sosyal, psikolojik ve fizyolojik rahatsızlıkların yaşanmasına neden olmaktadır. $\mathrm{Bu}$ çalışma; dışadönüklük, sosyal ağları kullanma sıklığı ve cinsiyetin üniversite öğrencileri arasında problemli sosyal ağ kullanımına etkisini incelemek amacıyla yapılmıştır. Çalışmaya 2017 - 2018 öğretim y1lı bahar döneminde bir devlet üniversitesinde okuyan 258 öğrenci katılmıştır. Verilerin toplanmasında Problemli Sosyal Ağ Kullanım Ölçeği, Beş Faktör Envanteri'nin dışadönüklük faktörü ve Sosyal Ağları Kullanma Sıklığı Ölçeği kullanılmıştır. Çoklu doğrusal regresyon analizi sonuçlarına göre dışadönüklük, sosyal ağları kullanma sıklığı ve cinsiyetten oluşan model, problemli sosyal ağ kullanımındaki değişimin \%6.4'ünü anlamlı olarak açıklamıştır. Araştırmada sosyal ağları kullanma sıklığının problemli sosyal ağ kullanımında anlamlı bir yordayıcı olduğu belirlenmiştir. Buna karşın, dışadönüklük ile cinsiyetin, üniversite öğrencilerinde problemli sosyal ağ kullanımının anlamlı yordayıcıları olmadıkları sonucuna ulaşılmıştır. Araştırmada elde edilen bulgulara dayalı olarak sosyal ağları kullanma sıklığının problemli sosyal ağ kullanımı üzerinde beklenenden daha düşük düzeyde bir etkiye sahip olduğu belirlenmiştir. Dolayısıyla problemli sosyal ağ kullanımı üzerinde kullanım sıklığı dışında başka faktörlerin de etkili olduğu söylenebilir. Ayrıca üniversite öğrencilerinde cinsiyetin problemli sosyal ağ kullanımı açısından bir risk faktörü olmadığı sonucuna ulaşılmıştır. Araştırmada dışadönüklük ile sosyal ağları kullanma sıklığı arasında pozitif yönde, düşük düzeyde ve anlamlı bir ilişski olmasına rağmen dışadönüklüğün problemli sosyal ağ kullanımı üzerinde etkili olmadığı belirlenmiştir. Bu sonuç; dışadönüklerin merak ve heyecan verici gelişmeleri kaçırma korkusu gibi kişilik özellikleri nedeniyle sosyal ağları amaçları doğrultusunda sık kullandıkları ancak sosyal doyum sağlamak için yüz yüze etkileşimi tercih ettikleri şeklinde değerlendirilmiştir.

Anahtar Kelimeler: Dışadönüklük, sosyal ağlar, problemli sosyal ağ kullanımı, dijital bağımlılık 


\section{ABSTRACT}

Problematic social network use is a trouble about a person's failure at self-control over the impulse to join social networks or resisting that impulse. This trouble leads to social, psychological, and physiological problems. The present study was conducted in order to assess the effects of extraversion, frequency of social network use, and gender on problematic use of social networks among university students. A hundred and fifty-eight students studying at a state university in the spring term of 2017-2018 academic year participated in the study. The Scale for Problematic Use of Social Network, extraversion dimension of the Five Factor Inventory, and the Scale for Frequency of Social Network Use were employed in gathering the data. According to the results of multiple linear regression analysis, the model comprising of extraversion, frequency of social network use, and gender explains significantly $6.4 \%$ of problematic use of social networks. Thus, it was detected that the frequency of social network use is a significant predictor to problematic use of social networks. However, it was found that neither extraversion nor gender is a significant predictor to problematic use of social networks. It was also found that the frequency of problematic social network use had less impact than expected on social network use; therefore, it can be said that there are some other factors affecting problematic social network use. Furthermore, it was found that the gender is not a risk factor on problematic social network use. Although there is a slight positive correlation between extraversion and problematic social network use, extraversion does not have a significant effect on problematic social network use. This result was that extroverts use social network due to the fear of missing important events, but they prefer face-to-face communication to satisfy their social desires.

Keywords: Extraversion, social networks, problematic use of social network, digital addiction

\section{EXTENDED ABSTRACT}

Social networks are today used widely by university students. Overuse of social networks results in social, psychological, and mental problems. This trouble is defined as problematic use of social network. Problematic use of social network is related to a person's failure at self-control over the impulse to join social networks and to resist the impulse to join social networks. The present study was carried out in order to examine the effect of extraversion, frequency of social network use, and gender on problematic use of social network among university students.

\section{Method}

\section{Participants}

The data for this study were composed of 258 persons studying at a state university in the spring term of 2017-2018 academic years. The data was collected from the students of various faculties so as to ensure the variety of data.

\section{Measures}

Scale for Problematic Use of Social Network. In the research, the students' level of problematic use of social network was determined by the Scale for Problematic Use of Social Network (SPUSN). SPUSN was developed by adapting the items of the Game Addiction Scale, 
which was introduced by Lemmens, Valkenburg and Peter (2009) to establish internet gaming disorders and translated into Turkish by Irmak and Erdoğan (2015), to social network use. SPUSN is seven-item, one dimensional, and five-point Likert type. The scale explains $50.32 \%$ of variance. Cronbach's Alpha internal consistency coefficient of the scale is 79 .

Extraversion Sub-Dimension of the Big Five Inventory. In the research, the extraversion of students was identified by 8 -item extraversion sub-dimension of 44 -item The Big Five Inventory developed by Benet-Martinez and John in 1998 under the title of The Big Five Inventory. The scale is a five-point Likert type. The Big Five Inventory was adapted into Turkish within the study to determine the self-identification profiles of people in 56 countries (Schmitt, Allik, McCrae, \& Benet-Martinez, 2007). In the present research study, the Cronbach's Alpha coefficient of extraversion sub-dimension was calculated as .76.

The Scale for Frequency of Social Network Use. In the research study, the students' frequency of social network use was established through The Scale for Frequency of Social Network Use developed by the researcher. The scale is five-point Likert type and onedimensional. It explicates $32.77 \%$ of variance. Cronbach's Alpha internal consistency coefficient of the scale was calculated as .77 .

\section{Results}

Regarding the multiple linear regression analysis, the model comprising of extraversion, frequency of social network use, and gender explains significantly $6.4 \%$ of problematic use of social network. Accordingly, the frequency of social network use is expectedly a significant predictor for problematic use of social network. It was revealed that extraversion and gender are not significant predictors for problematic use of social network. The regression equation obtained from the multiple regression analysis is such that:

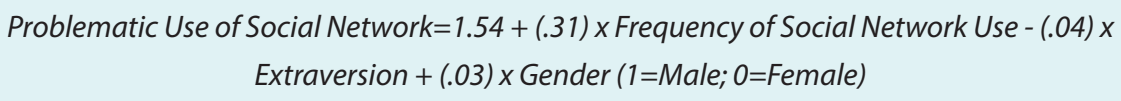

\section{Discussion}

Extravert students are social, lively, cheerful, dominant, assertive, and interested in others (Aydoğmuş, 2011; Costa \& McCrae, 1995; Tatlılıŏlu, 2014). It can be claimed that these traits lead social people to prefer face to face interactions to virtual ones. Therefore, it can be stated that extrovert personality traits impedes problematic use of social networks.

In the research, it was found that gender is not a significant predictor for problematic use of social networks. It is speculated that this state springs from the fact that social 
network use is intermittently sustainable in contrast to internet games, and responsibilities of university students is similar with regard to gender. Thus, problematic use of digital devices should be individually investigated based on digital device and application.

It was discovered in the research that there is positive, slight, and statistically significant correlation between extraversion and frequency of social network use. This result is striking because no significant association was established between extraversion and problematic use of social networks. This situation can be elucidated by the sensitivity of social students to others (Aydoğmuş, 2011; Costa \& McCrae, 1995; Tatılılığlu, 2014). Accordingly, social individuals use social networks more frequently due to their fear of missing what is going on around them. Furthermore, this situation can be explained by moral panic. Moral panic is defined as the social reaction to any person, event, and situation which is against common values and interests (Akdemir, 2016; Macintosh, 2008; Marwick, 2008; McRobbie \& Thorntom, 1995; Yıldız \& Sümer, 2010). Moral panic reactions arising over nationalism, violence to woman, child abuse, and other issues may be another reason for students to use social networks more frequently.

This topic should be investigated by different models to explain problematic use of social network based on the findings of the present study. Moreover, students should be informed about the harms resulting from overuse of social networks. It can be claimed that what harms emanate from problematic use of social networks within the context of right use of digital devices should be inserted into pre-university curriculum. 
Günümüzde, bilişim teknolojilerine dayalı gelişmelere bağlı olarak hayatın her alanında büyük değişimler yaşanmaktadır. İnsan hayatında meydana gelen değişim ve dönüşümlerin temelinde internet ve internete erişimi sağlayan bilgisayar, akllı cep telefonu ve tablet gibi dijital araçlar vardır. Bu araçlar, insan hayatınının vazgeçilemeyen bir unsuru haline gelmeye başlamıştır. İnternet ve internete erişimi sağlayan dijital araçlar, birçok iş ve işlemlerin daha kolay ve verimli bir şekilde yapılmasını sağlayarak insan hayatını kolaylaştırmaktadırlar. Ancak bu araçlar, insanlığın uğraşmak zorunda kaldığı birtakım yeni sorunları da beraberinde getirmiştir. Bu sorunlardan biri de, dijital bağıml111k sorunudur (Kesici, 2018).

Bağımlılık; belirli bir aktivite ya da madde kullanımına ilişkin alışkanlığa bağlı olarak kişinin fiziksel, sosyal, ruhsal, zihinsel sağlığını olumsuz etkileyen ve finansal durumu üzerinde yıkıcı etkilere neden olan dürtü şeklinde tanımlanmaktadır (Young, Yue ve Ying, 2011). Alkol, sigara, uyuşturucu vb. bağımlılıklar "madde bağımlılı̆̆ı"; kumar, aşırı spor, dijital araçlarda gereğinden fazla zaman geçirme vb. bağımlılıklar ise "davranış bağımlılığı" şeklinde sınıflandırılmaktadır (Günüç ve Kayri, 2010). Davranış bağımlılığı; herhangi bir maddeye bağlı olmaksızın, alışkanlığın sık tekrarı ile oluşan, madde bağımlılığında görülen sorunların gözlendiği, kişinin olumsuz etkilendiğini fark etmesine rağmen davranışı sürdürdüğü bir bağımlılık türüdür (Günüç ve Kayri, 2010; Kır ve Sulak, 2014; You, Kim ve Lee, 2017). Davranış bağımlılıklarından biri olan dijital bağımlılık; internet bağımlılığı, sosyal ağ bağımlılığ1, oyun bağımlılı̆̆ı, akıllı telefon bağımlılığı, vb. bağımlılıkları içinde bulunduran bir kavramdır (Cover, 2004; Jiang, Phalp ve Ali, 2015). Dijital bağımlılık; dijital araç kullanma güdüsüne karşı kendini kontrol edememe, dijital araçları kullanma dürtüsüne direnememe ile ilgili bir sorundur (Şentürk, 2017). Özellikle gençleri olumsuz olarak etkileyen dijital bağımlılık sorunu, günümüzde yaygın olarak görülmektedir. Bu sorun, ülkemizde de ciddi bir problem haline gelmiş ve sadece dijital bağımlılık sorunu olan bireylere hizmet sunan polikliniklerin açılmasına neden olmuştur (Sosyalmedya.co, 2019).

Web 2.0 teknolojilerine dayal1 Facebook, Twitter, Youtube ve Instagram gibi sosyal medya araçlarının geliştirilmesi, insanlara sosyal ihtiyaçlarını sanal ortamda karşılayabilme imkânı sunmuştur. Bu sosyal ağlar; kişilerin kendi profillerini oluşturdukları, arkadaşl1klar kurabildikleri, kendilerini sansürsüz olarak ifade edebildikleri, istekleri doğrultusunda kendilerini maskeleyebildikleri, kendilerini rahat ve özgür hissettikleri sanal platformlardır (Greenfield, 1999; Kuss ve Griffiths, 2011). Sosyal ağlarla sanal ortamda 
müzik, resim, animasyon, video gibi dosyalar paylaşılabilmektedir. Böylece bireyler kendilerini ifade edebilmekte, paylaşımda bulunabilmekte ve birbirleri ile iletişime geçebilmektedirler. Ayrıca kişi, sanal ortamda ilgisine göre çeşitli gruplara katılarak sosyal ihtiyaçlarını karşılayabilmektedir (Evans, 2008). Bu araçlar günümüzde bütün dünyada ve Türkiye'de oldukça sık kullanılmaktadırlar. We Are Social tarafından 2017 yılında yapılan bir araştırmada dünya nüfusunun \%37'sinin aktif sosyal medya kullanıcısı olduğu belirtilmiştir. Türkiye'de ise nüfusun \%60’ının (48 milyon kişi) aktif olarak sosyal medyayı kullandığı ve bu oranın sürekli arttığı belirtilmiştir (We Are Social and Hootsuite, 2018).

Sosyal ağların yaygın kullanımı, araştırmacıların ilgisini çekmiş ve konu ile ilgili çeşitli araştırmaların yapılmasına neden olmuştur. Yapılan araştırmalarda sosyal ağların aşırı kullanımının; akademik başarıyı (Kirschner ve Karpinski, 2010) ve bilişsel işlevi (Ophir, Nass ve Wagner, 2009) olumsuz etkilediği; iş performansını (Andreassen, Torsheim ve Pallesen, 2014) ve uyku kalitesini düşürdüğü (Wolniczak ve ark., 2013); yalnızl1k veya daha az sosyal gruplara katılma sorununa neden olduğu (Doğan ve Karakaş, 2016; Nyland, Marvez ve Beck, 2007); somatik belirtiler, kaygı bozukluğu, sosyal fonksiyon bozukluğu ve şiddetli depresyon (Koc ve Gulyagci, 2013) ile ilişkili olduğu ve dijital bağımlılık üzerinde yüksek düzeyde bir etkiye sahip olduğu (Kesici ve Fidan, 2018a) belirlenmiştir. Griffiths (2013), bazı sosyal ağ kullanıcılarının sosyal ağları aşırı bir şekilde kullanmaya bağlı olarak birçok sorun yaşadıklarını, ancak sosyal ağları aşırı kullanma davranışını sürdürmeye kendilerini mecbur hissettiklerini belirtmiştir. Bu nedenle birçok araştırmacı, sosyal ağların aşırı kullanımına bağlı olarak yaşanan olumsuzlukları davranış bağımlılığ 1 perspektifinde incelemişlerdir (Şentürk, 2017). Nitekim konunun literatürde sosyal ağ bağımlılığı (Griffiths, 2013) ya da sosyal medya bağımlılığ1 (Şentürk, 2017) şeklinde incelendiği görülmektedir. Bazı araştırmacılar ise konuyu daha özel bir sosyal ağ kullanımı bağlamında; Facebook bağımlılığı (Balci ve Gölcü, 2013), Instagram bağımlılığı (Kırcaburun, 2017) şeklinde incelemişlerdir. Sosyal ağların aşırı bir şekilde kullanılmasından kaynaklanan bu sorun, Amerikan Psikiyatri Birliği (APA) tarafindan yayınlanan DSM V'te (Diagnostic and Statiscal Manual of Mental Disorders; American Psychiatric Association, 2013) bağımlılık olarak alınmamıştır. Ancak bu sorunun bağımlılık olup olmadığı ile ilgili tartışmalar halen devam etmektedir (Şentürk, 2017). Dolayısıyla bu çalışmada kişinin sosyal, psikolojik, fiziksel ve zihinsel problemler yaşamasına rağmen sosyal ağları aşırı bir şekilde kullanma güdüsüne karşı kendini 
kontrol edememesi, sosyal ağlara katılma dürtüsüne direnememesi sorunu için problemli sosyal ağ kullanımı (PSAK) kavramı tercih edilmiştir.

Günlük yaşamın zorlukları nedeniyle oluşan stresin etkilerini azaltma, özyeterlik ve yaşam memnuniyeti sağlama, kendini ifade etme, yalnızlık duygusunu hafifletme gibi motivasyonlarla sosyal ağların aşırı bir şekilde kullanımı kişide olumsuz etkilere neden oluyorsa, PSAK'tan bahsedilebilir (LaRose, Lin ve Eastin, 2003; Xu ve Tan, 2012). Aş1r1 sosyal ağ kullanımına bağlı olarak yaşanabilecek olumsuzluklar Griffiths'in (2013) davranış bağımlılı̆̆ı için ortaya koyduğu kriterlere dayalı olarak açıklanabilir. Buna göre; PSAK bireyin yaşamında dikkat çekici bir hal alır, duygu durumunu etkiler. Sosyal ağlarda aldığı doyumu sürdürebilmesi için sosyal ağlara bağlanma miktarını arttırır. Sosyal ağlara erişimin engellenmesi kişide, hoş olmayan duygular ya da fiziksel belirtilerin görülmesine neden olur. Kişi, sosyal ağları kullanma davranışları nedeni ile çevresindeki bireylerle çatışma yaşar. Sosyal ağlardan uzun süre uzak kaldıktan sonra eski davranışları tekrar nükseder (Griffiths, 2013; Kesici ve Fidan, 2018b). Bu belirtiler, PSAK'a işaret eder ve kişinin sosyal ağları aşırı kullandığını gösterir. Nitekim literatürde PSAK, sosyal ağların aşırı kullanımından kaynaklanan bir sorun olarak tanımlanmıştır (Kirschner ve Karpinski, 2010; Koc ve Gulyagci, 2013; Şentürk, 2017). Ancak sosyal ağların aşırı kullanımının PSAK'a etkisin hangi düzeyde olduğu bilinmemektedir. Bu çalışmada sosyal ağların aşırı kullanılıp kullanılmadığına işaret eden sosyal ağların sık kullanımının PSAK üzerinde ne kadar etkili olduğu belirlenmeye çalışılmıştır.

Sosyallik ya da sosyal olma; toplum içinde yaşama, başkaları ile iletişim kurma ve etkileşimde bulunma insan doğasının bir gereğidir. Bir gruba ait olma, kendini ifade etme, sevme, sevilme gibi ilişkiler Maslow tarafından insanların temel ihtiyaçları arasında sayılmıştır (Akt. Demirel, 2011). Sağlıklı ilişkiler kurabilme ve ilişkilerini sürdürebilme önemli sosyal beceriler olarak değerlendirilmiştir (Bacanlı, 1999). Dahası bireyin çevresindekilerle iletişim kurması, onların ruh durumunu anlaması ve bir grup içinde iş birliği yapabilme becerisi çoklu zekâ kuramına göre sosyal zekâ ile ilişkilendirilmiştir (Bümen, 2011). Bu becerilerin yetersizliği örneğin sosyal olmama, sosyal fobi, çekingenlik ve yalnızlık ise önemli sorunlar olarak değerlendirilmiştir (Bacanlı 1999; Yakut ve Certel, 2016).

Sosyallik, psikolojide bir kişilik özelliği olarak değerlendirilmektedir. Kişiliği açıklayan özellik yaklaşımı; kişiliği, kişisel farklılıklara dayalı, gözlemlenebilen davranış- 
lardan hareketle açıklamaktadır (Basım, Çetin ve Tabak, 2009). Bu yaklaşıma dayalı beş faktör modeli, kişiliği; dişadönüklük, uyumluluk, sorumluluk (özdisiplin), nörotizm ve deneyime açıklık olarak adlandırılan beş faktörden oluşan bir model ile açıklamaktadır (Costa ve McCrae, 1995; Tatlılığlu, 2014). Kültürlerarası yapılan çalışmalarda bu modelin geçerliğini destekleyen sonuçlar elde edilmiştir (Schmitt, Allik, McCrae ve Benet-Martinez, 2007). Bu modelde sosyallik, dışadönüklük ile ilişkilendirilmiştir. Buna göre sosyal, enerjik, neşeli, baskın, iddialı ve başkalarına karşı ilgili olma gibi özellikler dışadönüklerin baskın özellikleri arasında sayılmıştır (Aydoğmuş, 2011; Costa ve McCrae, 1995; Tatlılığlu, 2014).

İnsanların çevirimiçindeki davranışlarını inceleyen çalışmalar, çevirimiçi ortamdaki davranışların kişilik ile ilişkili olduğunu göstermiştir (Mark ve Ganzach, 2014). Literatürde bu görüşü destekler nitelikte birçok kanıt elde edilmiştir. Liu, Preotiuc-Pietro, Samani, Moghaddam ve Ungar'a (2016) göre kişilik; resim, video, yazı vb. nesnenin sosyal ağlarda paylaşımında etkilidir. Kişilik, paylaşılacak nesnenin seçiminde adeta bir onay, norm işlevi görür. Bai, Zhu ve Cheng (2012) literatürdeki çalışmalara dayalı olarak sosyal medyadaki davranışlarla kişiliğin tahmin edilebileceğini belirlemişlerdir. Settanni, Azucar ve Marengo (2018), sosyal ağlarda kullanıcıların dijital izleri (sosyal ağlardaki aktiviteler, dil, demografik özellikler, fotoğraflar) ile kişiliği belirlemeye çalışan araştırmalar için bir metaanaliz çalışması yapmışlarıdır. Çalışmada dijital izlerin kişiliği tahmin etmek için kullanılabileceğini belirtmişlerdir. Yapılan araştırmalarda dışadönüklüğün; sosyal ağ kullanımının (Tan ve Yang, 2012) ve Facebook’taki arkadaş sayısının güçlü bir yordayıcısı (La Sala, Skues ve Grant, 2014), sosyal medya (Bai ve ark., 2012; Correa, Hinsley ve De Zuniga, 2010) ve Facebook kullanımı ile ilişkili (Hughes, Rowe, Batey ve Lee, 2012), sosyal medya kullanım motivasyonu üzerinde etkili (Avcilar ve Demirgunes, 2016) olduğu belirlenmiştir. Dolayısıyla dışadönüklerin, sosyal doyum sağlamak için sosyal ağları daha sık kullandıkları ve buna bağlı olarak dişadönüklüğün PSAK üzerinde etkili olabileceği düşünülmektedir. Buna karşın, dişadönüklüğün internet bağımlılığı üzerinde ters yönde ve düşük bir etkiye sahip olduğunu belirleyen çalışmalar da yapılmıştır (Çelik, Atak ve Başal, 2012; Kayiş ve ark., 2016; Servidio, 2014; Taş ve Ayas, 2015). Dolayısıyla, dışadönüklüğün PSAK üzerinde nasıl bir etkiye sahip olduğu bilinmemektedir. Bu araştırmada, dışadönüklüğün PSAK üzerinde etkili olup olmadı̆̆

Kültürel değerler, bireyin davranışlarında norm işlevi görerek bireyin davranışlarını 
etkilerler (Aydın ve Gürler, 2014). Toplum, kültürel bağlamda bireylere cinsiyete göre farklı sorumluluklar yükleyebilir. Bu nedenle cinsiyet, dijital araçların kullanım biçimini etkileyebilir (Ko, Yen, Chen, Chen ve Yen, 2005). Cinsiyete göre dijital araçları kullanma motivasyonundaki farklılıklar da dijital araç kullanımını etkiler (Kelleci, Güler, Sezer ve Gölbaşı, 2009). Dolayısıyla dijital araçların problemli kullanımında cinsiyetin etkili bir faktör olabileceği değerlendirilebilir. Nitekim, ergenlerden oluşan bir örneklemde dijital bağımlılığın bir türü olan dijital oyun bağımlılığında cinsiyetin önemli bir etken olduğu belirtilmiştir (Ko ve ark., 2005; Nazlıgül, Baş, Akyüz ve Yorulmaz, 2018). Cinsiyetin konu ile ilgili çalışmalarda araştırma sonuçlarını genelleştirmeyi engelleyebileceği, bu nedenle bu konudaki araştırmalarda cinsiyetin dikkat edilmesi gereken bir faktör olması gerektiği belirtilmektedir (Nazlıgül ve ark., 2018). Bu çalışmada cinsiyetin kültürel bağlam ve kullanım motivasyonlarından kaynaklanabilecek nedenlerle PSAK üzerinde de etkili olabileceği göz önüne alınarak cinsiyetin üniversite öğrencilerinde PSAK üzerinde etkili olup olmadığı belirlenmeye çalışılmıştır.

Sosyal ağların aşırı kullanımı, kullanıcıların akademik, fiziksel, sosyal ve psikolojik gelişimlerini olumsuz etkileyen bir durumdur (Andreassen ve ark., 2014; Doğan ve Karakaş, 2016; Kesici ve Fidan, 2018a; Kirschner ve Karpinski, 2010; Koc ve Gulyagci, 2013; Nyland ve ark., 2007; Ophir ve ark., 2009; Wolniczak ve ark., 2013). Bu sorun, başta ebeveynler olmak üzere eğitimcileri, sosyologları, psikologları ve yöneticileri ilgilendirmektedir. Bu nedenle konunun değişik yönleri ile incelenmesi ve gençleri bu olumsuz durumdan korumanın yolları araştırılmalıdır. Davranış bağımlılığı üzerinde; genetik yapı, sosyal ve psikolojik birçok faktörün etkili olduğu belirtilmiş̧tir (Chang ve Hung, 2012). Davranış bağımlılığı kapsamında ele alınan dijital bağımlılığın bir türü olarak değerlendirilen PSAK'ta da genetik, sosyal ve psikolojik birçok faktörün etkili olabileceği düşünülmektedir. Bu çalışmada PSAK üzerinde etkili olduğu düşünülen cinsiyetin, sosyal ağları kullanma sıklığının ve dışadönüklüğün üniversite öğrencilerinde PSAK'a etkisi incelenmiştir.

Bu araştırmanın, gençleri PSAK'ın olumsuz etkilerine karşı korumak amacıyla yapılacak çalışmalara katkı sağlayacağı ümit edilmektedir. Aşırı kullanım dışındaki diğer faktörlerin de PSAK üzerindeki etkisinin bilinmesi, PSAK'1 açıklamaya yönelik yeni çalışmaların tasarlanması konusunda araştırmacılara yol gösterebilir. Araştırmada dışadönüklüğün PSAK için bir risk faktörü olup olmadığı sınanmıştır. Böylece PSAK sorunu ile mücadelede odaklanılacak hedef kitlenin belirlenmesi hedeflenmiştir. Ayrıca bu 
araştırma ile daha önce yürütülen araştırmalardan farklı bir kültürde cinsiyetin PSAK üzerindeki etkisi de araştırılmıştır. Böylece konu ile ilgili veri çeşitliliği sağlanarak literatüre katkı sağlanmıştır.

\section{YÖNTEM}

\section{Katılımcılar}

Araştırmaya 2017-2018 öğretim yılı bahar döneminde Siirt Üniversitesi'nde okuyan 258 öğrenci katılmıştır. Araştırmada veri çeşitliliğini sağlamak amacıyla farklı fakülte ve yüksekokullardan veri toplanmıştır. Katılımcıların cinsiyeti ve okudukları fakülte/ yüksekokullarına göre dağılımları Tablo 1'de sunulmuştur.

Tablo 1. Katılımcıların Cinsiyete ve Okudukları Fakülte/Yüksekokula Göre Dağılımı

\begin{tabular}{llcc}
\hline & & $\boldsymbol{N}$ & $\boldsymbol{\%}$ \\
\hline \multirow{2}{*}{ Cinsiyet } & Erkek & 114 & 44.20 \\
& Kadın & 144 & 55.80 \\
& Veteriner Fakültesi & 76 & 29.50 \\
Fakülte/Yüksekokul & Fen-Edebiyat Fakültesi & 49 & 19.00 \\
& Beden Eğitimi ve Spor Yüksekokulu & 42 & 16.30 \\
& İngilizce Mütercimlik Tercümanlık & 91 & 35.30 \\
\hline
\end{tabular}

Tablo 1'de görüldüğü üzere katılımcıların yaklaşık \%56'sı ( $N=144)$ kadın, \%44'ü $(N=114)$ erkektir. Araştırmaya farklı alanlarda (sağlık, dil, spor, sosyal ve fen) eğitim gören öğrenciler katılmıştır. Katılımcıların yaklaşık \%30’u $(N=76)$ Veteriner Fakültesi’nde, \%35'i $(N=91)$ İngilizce Mütercimlik Bölümünde, \%19’u $(N=49)$ Fen Edebiyat Fakültesi'nin farklı bölümlerinde, \%16'sı $(N=42)$ ise Beden Eğitimi ve Spor Yüksekokulu'nda okuyan öğrencilerdir.

\section{Veri Toplama Araçları}

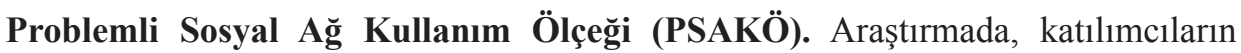
PSAK düzeyini belirlemek için Problemli Sosyal Ağ Kullanım Ölçeği (PSAKÖ) kullanılmıştır. Ölçek maddeleri; sorunlu dijital oyun oynama davranışlarını belirlemek için Lemmens, Valkenburg ve Peter (2009) tarafından geliştirilen, Irmak ve Erdoğan (2015) tarafından Türkçe’ye uyarlanan Dijital Oyun Bağımlılığı Ölçeği’ndeki maddeleri, sosyal ağ kullanımına göre değiştirilerek oluşturulmuştur. PSAKÖ; 7 maddeli, tek boyutlu ve "Hiçbir zaman (1)”, “Nadiren (2)”, “Bazen (3)”, “Sik sik (4)”, “Her zaman (5)”, şeklinde derecelendirilmiş Likert tipindedir. Katılımcılardan PSAK'ta ifade edilen so- 
runları son 6 ayda hangi sıklıkta yaşadıklarını değerlendirmeleri istenmektedir. Ölçekte bulunan maddelerden elde edilen puanların ortalaması hesaplanarak PSAK puanı elde edilmiştir. PSAK puanının yüksek olması, yüksek düzeyde PSAK'a işaret eder.

PSAKÖ’nin yapı geçerliğini belirlemek için araştırmada toplanan verilerle açımlayıc1 faktör analizi (AFA) yapılmıştır. Kaiser-Meyer-Olkin (KMO) değeri .83, Bartlett testi anlamlı $\left(\chi^{2}(15)=424.57, p<.01\right)$ bulunmuştur. Buna göre örneklem büyüklüğü yeterlidir ve maddeler arasında faktör analizi yapmak için de yeterli düzeyde bir ilişki vardır. AFA sonucu ölçeğin tek boyutlu bir yapıya sahip olduğu ve varyansın \%50.32'sini açıkladığı belirlenmiştir. PSAKÖ'de yer alan maddelerin faktör yük değerleri ile madde korelasyon katsayıları hesaplanmıştır. Elde edilen sonuçlar Tablo 2'de sunulmuştur.

Tablo 2. Problemli Sosyal Ağ Kullanım Ölçeği'ndeki Maddelere Ait Faktör Yük Değerleri ve Madde-Toplam Korelasyon Katsayıları

\begin{tabular}{lcc}
\hline Madde & $\begin{array}{c}\text { Faktör } \\
\text { Yükü }\end{array}$ & $\begin{array}{c}\text { Madde-Toplam } \\
\text { Korelasyon }\end{array}$ \\
\hline 1. Gün boyunca sosyal ağlarda bağlı kalmayı hiç düşündünüz mü? & .77 & .61 \\
2. Sosyal ağlar için harcadığınız zamanı giderek arttırdınız mı? & .79 & .65 \\
3. Günlük yaşamdan uzaklaşmak için sosyal ağlara katıldığınız oldu mu? & .74 & .59 \\
4. Aile bireyleri veya arkadaşlarınız sosyal ağlara katılma sürenizi azaltmada & .46 & .32 \\
başarısız oldu mu? & .73 & .57 \\
5. Sosyal ağlara katılmadığınız zaman kendinizi kötü hissettiniz mi? & .69 & .53 \\
6. Sosyal ağlara katılarak harcadığınız zaman konusunda aile bireyleri veya & .64 & .53 \\
arkadaşlarınızla kavga ettiniz mi? & & \\
7. Sosyal ağlara katılmak için diğer önemli faaliyetleri (okul, iş, spor gibi) ihmal & & \\
ettiniz mi? & & \\
\hline
\end{tabular}

Tablo 2'de görüldüğg̈ü üzere ölçekteki maddelerin faktör yük değerlerinden en yükseği .79, en düşüğü ise .46'dır. PSAKÖ'deki her bir maddenin madde-toplam korelasyon katsayılardan en düşüğü .32, en yükseği ise .65'dir. Ölçeğin Cronbach Alpha iç tutarlılık katsayısı .79 olarak hesaplanmıştır. Ayrıca her bir madde için alt ve üst grupları (\%27’lik uç grupları) kıyaslayan madde analizi yapılmıştır. Yapılan bağımsız örneklemler için $t$ testi sonuçlarına göre ölçekteki tüm maddelerin alt ve üst grupları anlamlı bir şekilde ayırdığı belirlenmiştir $(p<.01)$.

Araştırmaya katılan 100 öğrenciye PSAKÖ ile birlikte eş zamanlı olarak Young (1998) tarafından geliştirilen, Pawlikowski, Altstötter-Gleich ve Brand (2013) tarafından kısa forma dönüştürülen, 12 maddelik beşli Likert tipindeki Young İnternet Bağımlılığı Testi Kısa Formu (YIBBT-KF) uygulanmıştır (Kutlu, Savcı, Demir ve Aysan, 2016). Yİ- 
BT-KF'nin Türkçeye uyarlama çalışmasında ölçeğin Cronbach Alpha katsayısı .91 olarak hesaplanmış ve toplam varyansın \%39.52'sini açıkladığ 1 bildirilmiştir (Kutlu ve ark., 2016). Bu araştırmada YİBT-KF’nin Cronbach Alpha katsayısı .82 olarak hesaplanmıştır.

PSAKÖ ile YİBT-KF'den elde edilen puanlar arasındaki ilişkiyi belirlemek amacıya Pearson momentler çarpımı korelasyon katsayısı hesaplanmış ve puanlar arasında yüksek düzeyde, istatistiksel olarak anlamlı ve pozitif yönlü bir ilişki olduğu belirlenmiştir $(r(98)=.78 ; p<.01)$. Ayrıca PSAKÖ, 44 öğrenciye bir hafta arayla iki kez uygulanmıştır. Elde edilen puanlar arasında yüksek düzeyde, pozitif yönde ve istatistiksel olarak anlamlı bir ilişki olduğu belirlenmiştir $(r(42)=.91, p<.01)$.

Dışadönüklük. Araştırmada öğrencilerin dişadönüklük düzeyi, Benet-Martinez ve John'un (1998) The Big Five Inventory ismiyle geliştirdikleri, 44 maddelik Beş Faktör Envanteri'nin (BFE) 8 maddelik dişadönüklük faktörü ile belirlenmiştir. Ölçek, 5'li olarak derecelendirilmiş Likert tipindedir. BFE; 56 ülkede kişilerin kendilerini tanımlama profillerini belirlemeyi amaçlayan çalışma kapsamında Türkçe'ye uyarlanmıştır (Schmitt ve ark., 2007). Katılımcılardan dışadönüklük faktöründe yer alan maddelerin kendilerini hangi düzeyde tanımladıklarını "Hiç Tanımlamıyor (1)”, “Çok az tanımlıyor (2)”, ” Klsmen tanımlıyor (3)", “Oldukça tanımlıyor (4)” ve "Tamamen tanımlıyor (5)” şeklinde derecelendirilmiş ölçek ile değerlendirmeleri istenmektedir. Ölçekteki her bir madde için elde edilen puanlar toplanır ve madde sayısına bölünerek dışadönüklük puanı elde edilir. Elde edilen puanın yüksek olması, yüksek düzeyde dışadönüklüğü belirtir. Bu araştırmada dışadönüklük faktörü için Cronbach Alpha katsayısı .76 olarak hesaplanmıştır.

Sosyal Ağları Kullanma Sıklığı Ölçeği (SAKSÖ). Araştırmada öğrencilerin sosyal ağları aşırı kullanıp kullanmadıklarını belirlemek için araştırmacı tarafından geliştirilen Sosyal Ağları Kullanma Sıklığı Ölçeği kullanılmıştır. SAKSÖ; 9 maddelik, tek boyutlu ve “Hiç (1)”, “Nadiren (2)”, “Ara sıra (3)”, “Sık sık (4)”, “Sürekli (5)” şeklinde derecelendirilmiş Likert tipinde bir ölçektir. Katılımcılardan son 6 ayda hangi sıklıkta SAKSÖ’de ifade edilen amaçlarla sosyal ağları kullandıklarını değerlendirmeleri istenmektedir. Ölçekteki her bir madde için elde edilen puanlar toplanarak madde sayısına bölünüp sosyal ağları kullanma sıklığı puanı elde edilir. Sosyal ağları kullanma sıklığ1 puanının yüksek olması, yüksek düzeyde sosyal ağ kullanımına işaret eder.

Ölçeğin geliştirilme sürecinde ilk olarak sosyal ağları kullanma motivasyonlarının ne olduğunu belirlemek amacıyla literatür taraması yapılmıştır. Literatür taramasına da- 
yalı bir görüşme formu hazırlanmıştır. Daha sonra üniversite öğrencisi olup aktif sosyal ağ kullanıcısı olan dörder kişilik iki öğrenci grubu ile odak grup görüşmesi yapılmıştır. Görüşmeler sonucu SAKSÖ’de yer alacak maddeler belirlenmiştir. Buna göre ölçekte 10 maddenin yer alması kararlaştırılmıştır. Maddelerin uygunluğu konusunda iki bilgisayar ve öğretim teknolojileri öğretmeninin görüşü alınmıştır.

SAKSÖ’nün yapı geçerliğini belirlemek amacıyla araştırma kapsamında toplanan verilerle AFA yapılmıştır. Buna göre; Kaiser-Meyer-Olkin (KMO) değeri .75, Bartlett testi sonucu anlamlı $\left(\chi^{2}(45)=638.12, p<.01\right)$ bulunmuştur. Bu sonuçlara göre, faktör analizi için örneklem büyüklüğü yeterlidir. Ayrıca faktör analizi yapmak için maddeler arasında yeterli düzeyde bir ilişki vardır. Tek boyutlu bir yapıya sahip SAKSÖ, varyansın \%32.77'sini açıklamaktadır. Ancak, 6. maddenin (“interaktif oyunlar oynamak") faktör yükünün .19 ve madde-korelasyon katsayısının .15 olduğu belirlenmiştir. Elde edilen bu değerlerin yeterli düzeyde olmaması nedeniyle madde ölçekten çıkartılmış ve tekrar AFA yapılmıştır (Büyüköztürk, 2011). Tekrar yapılan AFA'ya göre; Kaiser-Meyer-Olkin (KMO) değeri .75 ve Bartlett testi sonucu anlamlı $\left(\chi^{2}(36)=609.69, p<.01\right)$ bulunmuştur. Tek boyutlu (9 maddelik) bir yapıya sahip ölçek, varyansın \%36.11'ini açıklamaktadır. AFA sonucunda SAKSÖ’de kalan her bir madde için faktör yük değerleri ile madde korelasyon katsayıları hesaplanmıştır. Elde edilen sonuçlar Tablo 3'de sunulmuştur.

Tablo 3. Sosyal Ağları Kullanma Sıklığı Ölçeği’ndeki Maddelere Ait Faktör Yük Değerleri ve Madde-Toplam Korelasyon Katsayılar1

\begin{tabular}{lcc}
\hline Madde & $\begin{array}{c}\text { Faktör } \\
\text { Yükü }\end{array}$ & $\begin{array}{c}\text { Madde-Toplam } \\
\text { korelasyon }\end{array}$ \\
\hline 1. Fotoğraf/Yazlı dosyası/video gibi nesneleri paylaşmak için & .72 & .57 \\
2. Gündemi takip etmek için & .52 & .36 \\
3. Sohbet etmek ve düşüncelerimi paylaşmak için & .66 & .51 \\
4. Yeni arkadaşlar edinmek için & .34 & .25 \\
5. Yabancı dil bilgimi geliştirmek için & .51 & .40 \\
7. Kendime özgü alan (profil, kişisel sayfa...) oluşturmak/güncellemek için & .63 & .49 \\
8. Arkadaşlarım ve yakınlarımla iletişim kurmak için & .69 & .54 \\
9. Okul dersleri ile ilgili araştırmalar yapmak için & .56 & .42 \\
10. İlgimi çeken konularda bilgi edinmek için & .64 & .50 \\
\hline
\end{tabular}

Tablo 3’te görüldüğü üzere ölçekte kalan maddelerin faktör yük değerlerinden en yüksek olanı .72, en düşük olanı ise .34'tür. Madde-toplam korelasyon katsayılarından en düşük olanı .25 , en yükseği ise $.57^{\prime}$ 'dir. SAKSÖ’de bulunan her bir madde için alt ve üst grupları (\%27’lik uç grupları) kıyaslayan madde analizi yapılmıştır. Yapılan bağım- 
sız örneklemler için $t$ testi sonuçlarına göre maddelerin tümünün alt ve üst grupları anlamlı bir şekilde ayırdığı görülmüştür $(p<.01)$. Ölçeğin Cronbach Alpha iç tutarlılık katsayısı .77 olarak hesaplanmıştır.

\section{İşlem}

Verilerin toplanabilmesi için ilgili fakülte/yüksekokullarının yöneticileri ile görüşmeler yapılarak ölçeklerin uygulanabilmesi için gerekli izinler alınmıştır. Ayrıca bu görüşmelerde araştırmaya katkı sağlayacak öğretim görevlileri/üyeleri belirlenmiştir. Veriler araştırmaya katkı sunmayı kabul eden öğretim görevlileri/üyeleri tarafından kendi derslerinde toplanmıştır. Araştırmaya katkı sağlayan öğretim görevlileri/üyeleri öğrencilere araştırmanın amacı hakkında bilgiler verip araştırmaya katılmalarını istemişlerdir. Araştırmaya katılım, gönüllülük esasına göre yapılmıştır. Veriler SPSS 18.0 ile çözümlenmiştir. Verilerin çözümlenmesinde korelasyon ve çoklu doğrusal regresyon analizleri kullanılmıştır.

\section{BULGULAR}

Araştırmada, katılımcıların sosyal ağları kullanma sıklığı, dışadönüklük ve PSAK düzeylerini belirlemek için kullanılan ölçeklerden elde edilen puanlara ait ortalama ve standart sapma değerleri hesaplanmıştır. Elde edilen sonuçlar Tablo 4'te sunulmuştur.

Tablo 4. Katılımcıların Sosyal Ağları Kullanma Sıklığı, Dışadönüklük Düzeyleri ve Problemli Sosyal A $\breve{g}$ Kullanma Puan Ortalamaları, Standart Sapma Değerleri

\begin{tabular}{lccc}
\hline & N & Ort. & SS \\
\hline Sosyal Ă̆ Kullanım Sıklığı & 258 & 3.09 & 0.71 \\
Dişadönüklük & 258 & 3.28 & 0.74 \\
Problemli Sosyal Ă̆ Kullanımı & 258 & 2.37 & 0.85 \\
\hline
\end{tabular}

Tablo 4'te görüldüğü üzere, sosyal ağları kullanma sıklığının puan ortalaması 5.00 üzerinden 3.09 olarak hesaplanmıştır. Dışadönüklük puan ortalaması 5.00 üzerinden 3.28 ve PSAK puan ortalaması ise 5.00 üzerinden 2.37 olarak hesaplanmıştır.

Araştırmada değişkenler arasında nasıl bir ilişki olduğunu belirlemek için korelasyon analizi yapılmıştır. Korelasyon analizi sonucu elde edilen Pearson momentler çarpımı korelasyon katsayıları Tablo 5 'te sunulmuştur. 
Tablo 5. Araştırmanın Değiş̧kenleri Arasındaki İlişkileri Belirlemek Amacıyla Yapılan Korelasyon Analizi Sonuçları

\section{(1)}

(1) Problemli Sosyal Ağ Kullanımı

(2) Sosyal Ağ Kullanım Sıklığı

(3) Dışadönüklük

(4) Cinsiyet

${ }^{*} p<.05$

(2)

(3)

Tablo 5'te görüldüğü üzere PSAK ile sosyal ağ kullanım sıklığı arasında düşük düzeyde, pozitif yönde ve anlamlı bir ilişki vardır $(r(256)=.25, p<.05)$. PSAK ile dişadönüklük arasında anlamlı bir ilişki yoktur $(r(256)=.03, p>.05)$. Kadın ya da erkek olmanın PSAK ile anlamlı bir ilişki göstermediği görülmüştür $(r(256)=-.01, p>.05)$. Sosyal ağları kullanma sıklığg ile dışadönüklük arasında pozitif yönde, düşük düzeyde ve anlamlı bir ilişki vardır $(r(256)=.29, p<.05)$. Sosyal ağları kullanma sıklığı ile cinsiyet arasında anlamlı bir ilişkinin olmadığı belirlenmiştir $(r(256)=-.10, p>.05)$. Dışadönüklük ile cinsiyet arasında da anlamlı bir ilişkinin olmadığı tespit edilmiştir $(r(256)$ $=-.05, p>.05)$.

Araştırmada katılımcıların sosyal ağları kullanma sıklığı, dışadönüklük düzeyleri ve cinsiyetin PSAK'a etkisini belirlemek amacıyla çoklu doğrusal regresyon analiz yapılmıştır. Wooldridge (2013), regresyon analizinde normallik koşulunun sağlanabilmesi için modeldeki her bir değişken için en az 20 verinin olması gerektiğini belirtmiştir. Dolayısıyla (katılımcı sayısı gözönüne alındığında) regresyon analizi için normallik koşulu sağlanmıştır. Sosyal ağ kullanım sıklığı, dışadönüklük ve cinsiyet değişkenlerine ait VIF değerlerinin 10'dan küçük, Tolerans değerlerinin .2'den büyük olduğu görülmüştür. Böylece değişkenler arasında çoklu bağlantı sorunu olmadığı belirlenmiştir (Alpar, 2012; Tabachnick ve Fidell, 2007). Korelasyon analizi ile değişkenler arasında doğrusal bir ilişki olduğu belirlenmiştir. Regresyon modeline ait hata terimlerinin dağılım grafikleri çıkarılarak incelenmiştir. Hata terimlerinin 0 (sıfır) ortalama ve sabit varyansa sahip oldukları ve yaklaşık normal dağıldığı belirlenmiştir. Böylece çoklu doğrusal regresyon analizinin bütün şartları sağlanmıştır (Alpar, 2012; Tabachnick ve Fidell, 2007). Yapılan çoklu doğrusal regresyon analizinde elde edilen sonuçlar Tablo 6'te sunulmuştur. 
Tablo 6. Üniversite Öğrencilerinde Dışadönüklük, Sosyal Ağları Kullanma Sıklı̆̆ı ve Cinsiyetin Problemli Sosyal Ağ Kullanımına Etkisini Belirlemek Amacıyla Yapılan Regresyon Analizi Sonuçları

\begin{tabular}{lccccc}
\hline Model & $\boldsymbol{B}$ & Standart Hata & $\boldsymbol{\beta}$ & $\boldsymbol{t}$ & $\boldsymbol{p}$ \\
\hline Sabit & 1.54 & .29 & & 5.26 & $<.001$ \\
Sosyal Ă̆ Kullanım Siklı̆̆1 & .31 & .07 & .26 & 4.14 & $<.001$ \\
Dişadönüklük & -.04 & .07 & -.04 & -.67 & .49 \\
Cinsiyet & .03 & .10 & .01 & .29 & .77 \\
\hline
\end{tabular}

$R^{2}=.06 ; F(3,254)=5.83 ; p<.001$. Cinsiyet: Erkek $=1$, Kadın $=0$.

Tablo 6'da görüldüğü üzere oluşturulan regresyon modeli, PSAK'taki değişimin \%6.4'ünü açıklamaktadır $\left(R^{2}=.06, F(3,254)=5.83, p<.001\right)$. Çoklu regresyon analizi sonucuna göre, cinsiyet, sosyal ağları kullanma sıklığı ve dişadönüklüğün PSAK'1 yordamasına ilişkin regresyon denklemi aşağıda sunulmuştur.

\section{Problemli sosyal ağ kullanımı $=1.54+(.31) x$ Sosyal ağları kullanım sıklığ $-(.04) x$}

$$
\text { Dışadönüklük + (.03) } x \text { Cinsiyet }(1=\text { Erkek, } 0=\text { Kadın })
$$

\section{TARTIŞMA}

$\mathrm{Bu}$ araştırma, üniversitede okuyan öğrencilerin dişadönüklük, cinsiyet ve sosyal ağları kullanma sıklığının PSAK'a etkisini belirlemek amacıyla yapılmıştır. Bu amaçla çoklu doğrusal regresyon analizi yapılmıştır. Araştırmada sosyal ağları kullanma sıklığı, dışadönüklük ve cinsiyetten oluşan model, PSAK'ın \%6.4'ünü anlamlı olarak açıklamaktadır.

Yapılan regresyon analizinde sosyal ağları kullanma sıklığının PSAK'ın anlamlı bir yordayıcısı olduğu belirlenmiştir. Sosyal ağları kullanma sıklığındaki artış, PSAK düzeyini yükseltecek bir etkiye neden olmaktadır. Bu bulgu beklentilerle uyumludur. Çünkü, PSAK sosyal ağların aşırı bir şekilde kullanımı ile ilgili bir sorundur. Ancak, kullanım sıklığının PSAK'a etkisinin maksimum \%31.5 olabileceği belirlenmiştir. Kullanım sıklığının PSAK üzerinde belirlenen etki düzeyinin, PSAK'ın sosyal ağların aşırı kullanımından kaynaklanan bir sorun olduğu göz önüne alındığında, beklentilerin altında olduğu söylenebilir. Bu nedenle PSAK üzerinde önemli düzeyde etkili olan başka faktörlerin olduğu söylenebilir.

Araştırmada, dışadönüklüğün PSAK üzerinde anlamlı bir etkiye sahip olmadığı belirlenmiştir. Dışadönük öğrencilerin sosyal doyum elde etmek için sosyal ağları sık kullandıkları ve bunun PSAK'a neden olacağına yönelik beklentiler, araştırmanın bu sonu- 
cu ile çelişmektedir. Bu durumun sosyal, enerjik, neşeli, baskın, iddialı ve başkalarına karşı ilgili olmaları nedeniyle (Aydoğmuş, 2011; Costa ve McCrae, 1995; Tatlılıoğlu, 2014) dişadönüklerin sosyal doyum için çevirimiçi etkileşim yerine yüz yüze etkileşimi tercih etmelerinden kaynaklanmış olabileceği düşünülmektedir. Literatürde, araştırmanın bu sonucu ile ilişkili olduğu değerlendirilen ve dışadönüklüğün internet bağımlılığı üzerinde ters yönde ve düşük bir etkiye sahip olduğunu belirten çalışmalar vardır (Bkz., Çelik ve ark., 2012; Kayiş ve ark., 2016; Servidio, 2014; Taş ve Ayas, 2015). Bu araştırma sonuçları, dışadönüklüğün PSAK üzerindeki etkisinin incelendiği bu çalışmanın bulgusu ile uyumlu değildir. D1şadönüklügüü internet bağımlılığg üzerinde etkili olmasına karşın PSAK üzerinde etkili olmamasının nedeninin, problemli internet kullanımının PSAK'a göre daha genel bir durumu ifade etmesinden kaynaklanabileceği düşünülmektedir. Problemli internet kullanımı; oyun, sosyal ăg, alışveriş, vb. birçok dijital uygulamaların problemli kullanımlarını içinde barındırır.

Araştırmada, cinsiyetin (kadın ya da erkek olmanın) PSAK üzerinde anlamlı bir etkiye sahip olmadığı belirlenmiştir. Yani, cinsiyet değişkeni PSAK'ın anlamlı bir yordayıcısı değildir. Bu bulgu, literatürdeki bazı araştırma sonuçlarıyla uyumludur (Kırcaburun, 2017; Ünal, 2015). Ancak bu konuda erkeklerin lehine anlamlı farklılık olduğunu belirleyen çalışmalar (Çam ve İşbulan, 2012) olduğu gibi kadınların lehine anlamlı farkl1lık olduğunu belirleyen çalışmalar (Andreassen, Torsheim, Brunborg ve Pallesen, 2012) da vardır. Bu konuda, dijital oyun bağımlılığında olduğu gibi bir uzlaşma yoktur. Sosyal ağların ve dijital oyunların kullanım biçimleri göz önüne alındığında; oyun oynama süreci kesintisiz, sosyal ağ kullanımı ise kesintili aralıklarla gerçekleştirilebilen eylemlerdir. Ayrıca toplumun yüklediği ve cinsiyete göre sosyal ağ kullanımını etkileyebilecek bir durum görülmemektedir. Dolaysıyla kültürel bağlam ve sosyal ağların kullanım biçimi göz önüne alındığında cinsiyetin üniversite öğrencilerinde PSAK üzerinde etkili bir faktör olmadığı söylenebilir.

PSAK üzerinde anlamlı bir etkiye sahip olmayan dışadönüklük ile PSAK üzerinde anlamlı bir etkiye sahip sosyal ağları kullanma sıklığı arasında pozitif yönde, düşük düzeyde ve istatistiksel olarak anlamlı bir ilişkinin belirlenmesi, araştırmanın dikkat çeken bir bulgusudur. Literatürde araştırmanın bu bulgusunu destekler nitelikte çalışmalar yapılmıştır (Bai ve ark., 2012; Correa ve ark., 2010; Hughes ve ark., 2012; La Sala ve ark., 2014). Bu durumun, dışadönüklerin başkalarına karşı ilgili olma özelliğinden (Aydoğmuş, 2011; Costa ve McCrae, 1995; Tatlılığlu, 2014) kaynaklandığı düşünülmektedir. 
Bu özellik, dışadönüklerde "gelişmeleri kaçırma korkusu” ile ifade edilen bir kaygının oluşmasına neden olur (Şentürk, 2017). Çevrelerinde yaşanan gelişmeleri kaçırma korkusu, heyecan verici ve ilginç deneyimlerden mahrum kalma korkusu gibi duygular, d1şadönüklerin sosyal ağları daha sık kullanmalarının bir nedeni olabilir. Ayrıca dışadönüklerin baskın özelliklerinden biri de başkalarına karşı duyarlı olmalarıdır (Aydoğmuş, 2011; Costa ve McCrae, 1995; Tatlılığlu, 2014). Bu özellikleri nedeniyle sosyal ağlarda oluşturulan ahlaki panik (moral panic), dışadönük öğrencilerin sosyal ağları daha sık kullanmalarının bir nedeni olabilir. Ahlaki panik; toplumdaki ortak değerlere ve çıkarlara ters kişi, olay ve durumlara (milliyetçilik, kadına şiddet, çocuk istismarı, moda vb.) gösterilen toplumsal tepkilerdir (Akdemir, 2016; Macintosh, 2008; Marwick, 2008; McRobbie ve Thorntom, 1995; Yıldız ve Sümer, 2010). Gelişmeleri kaçırma korkusu veya ahlaki panik gibi nedenlerle sosyal ağları daha sık kullandığı düşünülen dışadönüklerin, sosyal ağları kendi amaçlarını gerçekleştirmek için kullandıkları söylenebilir. Belirli bir amaç doğrultusunda gerçekleştirilen sosyal ağ kullanımı, dışadönüklerin sosyal ağları problemli kullanma eşiğinin üstüne çıkmasını engeller. Bu nedenle dışadönüklüğün PSAK üzerinde etkili bir faktör olmadığı sonucu çıkarılabilir.

Araştırmada, üniversite öğrencilerinde PSAK'1 açıklamaya yönelik oluşturulan regresyon modeli, PSAK’ın yanlızca \%6.4'ünü açıklamıştır. Dolayısıyla stres, iletişim becerileri, psikolojik etkenler, kişilik özellikleri, düşük sosyal destek, vb. birçok faktör PSAK üzerinde etkili olabilir. Bu nedenle araştırmacılara, farklı değişkenlerden oluşan modellerle PSAK'1 araştırmaları önerilir. PSAK sorunu yaşayan kişilerin sosyal ağları kullanma motivasyonlarını belirlemeye yönelik yapılacak çalışmalar da alana katkı sağlayacaktır. Bu araştırmada, kişilik özelliklerinden yanlızca dışadönüklügüun PSAK üzerindeki etkisi araştırılmıştır. Diğer kişilik özelliklerinin araştırmaya dahil edilmemesi araştırmanın bir sınırlılığıdır. Bu nedenle konu, farklı kişilik özellikleri göz önüne alınarak daha geniş örneklemlerle araştırılmalıdır.

Araştırmada elde edilen sonuçlar doğrultusunda, üniversite öğrencilerini PSAK'ın olumsuz etkilerinden korumak için sosyal ağları aşırıya kaçmadan, ihtiyaçlar doğrultusunda kullanmaya yönelik bir anlayışın geliştirilmesi gerektiği söylenebilir. Bu amaçla öğrencilerin sosyal ağları eğitim ve bilgi edinme gibi amaçlar doğrultusunda kullanmaya yönelik tutumları geliştirilmeli ve bilinçli dijital araç kullanıcısı olmaları için çaba harcanmalıdır. Sosyal ağların problemli kullanımında ne gibi olumsuzlukların yaşanabileceği konusu, üniversite öncesi eğitim kurumlarının programlarına yansıtılmalıdır. Da- 
hası, yetkili veya gönüllü kurumların iş birliği ile toplumu bilinçlendirme ve konu ile ilgili farkındalık düzeyini artırmaya yönelik reklam, bilgilendirici videolar vb. çalışmalar yürütülmelidir.

Davranış bağımlılı̆̆ı kategorisinde değerlendirilen dijital bağımlılığın farklı türleri her ne kadar birbirlerine benzerlik gösterseler de birbirlerinden ayrışan yönleri de vardır. Örneğin, bu araştırmada cinsiyetin PSAK üzerinde belirlenen etkisi ile literatürde cinsiyetin dijital oyun bağımlılığına etkisini belirleyen çalışmaların sonuçlarının birbirinden farklı olduğu görülmüştür. Benzer şekilde bu araştırmada belirlenen, dışadönüklüğün PSAK üzerindeki etkisi ile literatürde dışadönüklüğün internet bağımlılığına etkisini belirleyen çalışma sonuçları da birbirinden farklıdır. Bu nedenle dijital bağımlılık türlerinin ayrı ayrı incelenmesinin doğru bir yaklaşım olacağı söylenebilir.

Finansal Destek: Yazar bu çalışma için finansal destek almamıştır.

\section{Kaynakça}

Akdemir, N. (2016, 12 Aralık). Medya ve iletişim temelinde sosyal medya hareketliliği; "milliyetçilik" ve nefret söylemi. Erişim adresi: $h$ ttps://scholar.google.com.tr/scholar?hl=tr\&q=Medya+ve+\%C4\%B0leti $\%$ C $5 \% 9$ Fim + Temelinde+Sosyal+Medya+Hareketlili $\%$ C4\% $\%$ Fi $\% 3 \mathrm{~B}+\%$ E2 $\% 80 \% 9$ CMilliyet $\%$ C3\%A7ilik $\%$ E2\%80\%9D+ve+\%E2\%80\%9CNefret + S\%C3\%B6ylemi\%E2\%80\%9D.+\&btn$\mathrm{G}=\& \mathrm{lr}=$.

Alpar, R. (2012). Applied statistics and validity-reliability with examples from sports, health and education sciences [Spor, sağllk ve eğitim bilimlerinden örneklerle uygulamall istatistik ve geçerlilik-güvenirlik] (2. Bask1). Ankara: Detay.

American Psychiatric Association (2013). Diagnostic and statistical manual of mental disorders. (5. bask1). Washington, DC: American Psychiatric Publishing.

Andreassen, C. S., Torsheim, T., Brunborg, G. S. ve Pallesen, S. (2012). Development of a Facebook addiction scale. Psychological Reports, 110(2), 501-517.

Andreassen, C. S., Torsheim, T. ve Pallesen, S. (2014). Use of online social network sites for personal purposes at work: Does it impair self-reported performance? Comprehensive Psychology, 3, 1-21.

Avcilar, M. Y. ve Demirgunes, B. K. (2016). Analyzing the effects of personality traits on motivations for using social media. Journal of Management Marketing and Logistics, 3(3), 251-271.

Aydın, M. Z. ve Gürler, Ş. A. (2014). Okulda değerler eğitimi. Ankara: Nobel.

Aydoğmuş, C. (2011). The impacts of follower psychological empowerment and perceptions of transformational leadership on the relationship between follower personality and job satisfaction (Yayınlanmamış Doktora Tezi). Hacettepe Üniversitesi, Ankara.

Bacanl, H. (1999). Sosyal beceri eğitimi. Ankara, Nobel.

Bai, S., Zhu, T. ve Cheng, L. (2012). Big-five personality prediction based on user behaviors at social network sites. Erişim adresi: https://arxiv.org/abs/1204.4809. Erişim tarihi: 13 Temmuz 2018.

Balci, Ş. ve Gölcü, A. (2013). Facebook addiction among university students in Turkey:" Selcuk University example". Selçuk Üniversitesi Türkiyat Araştırmaları Dergisi, 1(34), 255-278. 
Basım, H. N., Çetin, F. ve Tabak, A. (2009). The relationship between big five personality characteristics and conflict resolution approaches. Turkish Journal of Psychology, 24(63), 35-37.

Benet-Martinez, V. ve John, O. P. (1998). Los Cinco Grandes across cultures and ethnic groups: Multitrait-multimethod analyses of the Big Five in Spanish and English. Journal of Personality and Social Psychology, 75, 729-750.

Bümen, N. T. (2011). Çoklu zekâ kuramı. Ö. Demirel (Ed.), Eğitimde yeni yönelimler içinde. (ss.1-38). Ankara: Pegem yayınları.

Büyüköztürk, Ş. (2011). Sosyal bilimler için veri analizi el kitabı (15. bask1). Ankara: Pegem Akademi. Çelik, S., Atak, H. ve Başal, A. (2012). Predictive role of personality traits on internet addiction. Turkish Online Journal of Distance Education, 13(4), 10-24.

Chang J. P. C. ve Hung, C. C. (2012). Problematic internet use. Erişim adresi: http://iacapap.org/ wpcontent/uploads/H.6-INTERNET-ADDICTION-072012.pdf. Erişim tarihi: 10 Haziran 2018.

Correa, T., Hinsley, A. W. ve De Zuniga, H. G. (2010). Who interacts on the Web? The intersection of users' personality and social media use. Computers in Human Behavior, 26(2), 247-253.

Costa, Jr. P.T. ve McCrae, R.R. (1995). Domains and facets: Hierarchical personality assessment using the revised NEO personality inventory. Journal of Personality Assessment, 64(1), 21-50.

Cover, R. (2004). Digital addiction: The cultural production of online and video game junkies. Media International Australia incorporating Culture and Policy, 113(1), 110-123.

Çam, E. ve İşbulan, O. (2012). A new addiction for teacher candidates: Social networks. Turkish Online Journal of Educational Technology-TOJET, 11(3), 14-19.

Demirel, Ö. (2011). Kuramdan uygulamaya eğitimde program geliştirme (16. bask1). Ankara: Pegem.

Doğan, U. ve Karakaş, Y. (2016). Lise öğrencilerinin sosyal ağ sitleri kullanımının yordayıcısı olarak yalnızlı. Sakarya University Journal of Education, 6(1), 57-71.

Evans, D. (2008). Social media marketing an hour a day. Indiana: Wiley Publishing.

Greenfield, D. N. (1999). Psychological characters of compulsive internet use: A preliminary analysis. Cyberpsychology \& Behavior, 2(2), 403-412.

Griffiths, M. D. (2013). Social networking addiction: Emerging themes and issues. Journal of Addiction Research \& Therapy, 4(5), 1-2.

Günüç, S. ve Kayri, M. (2010). Türkiye'de internet bağımlılık profili ve internet bağımlılık ölçeğinin geliştirilmesi: Geçerlik-güvenirlik çalışması. Hacettepe Üniversitesi Eğitim Fakültesi Dergisi, 39, 220-232.

Hughes, D. J., Rowe, M., Batey, M. ve Lee, A. (2012). A tale of two sites: Twitter vs. Facebook and the personality predictors of social media usage. Computers in Human Behavior, 28(2), 561-569.

Irmak, A. ve Erdoğan, S. (2015). Dijital Oyun Bağımlılı̆̆ Ölçeği Türkçe formunun geçerliliği ve güvenilirliği. Anadolu Psikiyatri Dergisi,16(Özel sayı 1), 10-18.

Jiang, J., Phalp, K. T. ve Ali, R. (2015, 13 Aralık). Digital addiction: Gamification for precautionary and recovery requirements. Erişim adresi: http://eprints.bournemouth.ac.uk/21887/1/04-Posters.pdf

Kayiş, A. R., Satici, S. A., Yilmaz, M. F., Şimşek, D., Ceyhan, E. ve Bakioğlu, F. (2016). Big five-personality trait and internet addiction: A meta-analytic review. Computers in Human Behavior, 63, 35-40.

Kesici, A. (2018). Durkheim'in görüşleri doğrultusunda küreselleşme olgusu ve eğitimin küresel işlevi. Atatürk Üniversitesi Sosyal Bilimler Enstitüsü Dergisi, 22(2), 977-988.

Kesici, A. ve Tunç, N. F. (2018a). Investigating the digital addiction level of the university students according to their purposes for using digital tools. Universal Journal of Educational Research, 6(2), 235-241.

Kesici, A. ve Tunç, N. F. (2018b). The development of the Digital Addiction Scale for the university students: Reliability and validity study. Universal Journal of Educational Research, 6(1), 91-98. 
Kelleci, M., Güler, N., Sezer, H. ve Gölbaşı, Z. (2009). Lise öğrencilerinde internet kullanma süresinin cinsiyet ve psikiyatrik belirtiler ile ilişkisi. TAF Preventive Medicine Bulletin, 8(3), 223-230.

Kır, İ. ve Sulak, Ş. (2014). Eğitim fakültesi öğrencilerinin internet bağımlılık düzeylerinin incelenmesi. Electronic Journal of Social Sciences, 13(51).

Kırcaburun, K. (2017). Üniversite ögrencilerinde Instagram bă̆ımlıllğı, kişilik özellikleri ve kendini sevme arasındaki ilişkinin incelenmesi (Yayımlanmamış Yüksek Lisans Tezi). Sakarya Üniversitesi, Sakarya.

Kirschner, P. A. ve Karpinski, A. C. (2010). Facebook and academic performance. Computers in Human Behavior, 26, 1237-1245.

Ko, C. H., Yen, J. Y., Chen, C. C., Chen, S. H. ve Yen, C. F. (2005). Gender differences and related factors affecting online gaming addiction among Taiwanese adolescents. The Journal of Nervous and Mental Disease, 193(4), 273-277.

Koc, M. ve Gulyagci, S. (2013). Facebook addiction among Turkish college students: The role of psychological health, demographic, and usage characteristics. Cyberpsychology, Behavior, and Social Networking, 16(4), 279-284.

Kuss, D. J. ve Griffiths, M. D. (2011). Online social networking and addiction-A review of the psychological literature. International Journal of Enviromental Research and Public Healty, 8(9), 3528-3552.

Kutlu, M., Savc1, M., Demir, Y. ve Aysan, F. (2016). Young internet bağımlılı̆̆1 testi kısa formunun Türkçe uyarlaması: Üniversite öğrencileri ve ergenlerde geçerlilik ve güvenilirlik çalışması. Anadolu Psikiyatri Dergisi, 17(1), 69-76.

La Sala, L., Skues, J. ve Grant, S. (2014). Personality traits and Facebook use: The combined/interactive effect of extraversion, neuroticism and conscientiousness. Social Networking, 3(5), 211.

LaRose, R., Lin, C. A. ve Eastin, M. S. (2003). Unregulated internet usage: Addiction, habit, or deficient self-regulation?. Media Psychology, 5(3), 225-253.

Lemmens, J. S., Valkenburg, P. M. ve Peter, J. (2009). Development and validation of a game addiction scale for adolescents. Media Psychology, 12(1), 77-95.

Liu, L., Preotiuc-Pietro, D., Samani, Z. R., Moghaddam, M. E. ve Ungar, L. (2016, May.). Analyzing personality through social media profile picture choice. Tenth International AAAI Conference on Weblogs and Social Media (ICWSM), Cologne, Germany.

Macintosh A. (2008). The emergence of digital governance. Significance, 5(4), 25-48.

Mark, G. ve Ganzach, Y. (2014). Personality and Internet usage: A large-scale representative study of young adults. Computers in Human Behavior, 36, 274-281.

Marwick A. E. (2008). To catch a predator? The myspace moral panic. First Monday, 13(6). Erişim adresi: http://firstmonday.org/article/view/2152/1966

McRobbie, A. ve Thorntom, S. L. (1995). Rethinking'moral panic for multi-mediated social worlds. The British Journal of Sociology, 46(4), 559-574.

Nazlıgül, M. D., Baş S., Akyüz, Z. ve Yorulmaz, O. (2018). Internet gaming disorder and treatment approaches: A systematic review. Addicta: The Turkish Journal On Addictions, 5, 13-35.

Nyland, R., Marvez, R. ve Beck, J. (2007, February). MySpace: Social networking or social isolation? The Midwinter Conference of the Association for Education in Journalism and Mass Communication, Reno, NV, USA.

Ophir, E., Nass, C. ve Wagner A. D. (2009). Cognitive control in media multitaskers. PNAS, 106(37), 15583-15587.

Pawlikowski, M., Altstötter-Gleich, C., \& Brand, M. (2013). Validation and psychometric properties of a short version of Young's Internet Addiction Test. Computers in Human Behavior, 29(3), 1212-1223. 
Schmitt, D. P., Allik, J., McCrae, R. R. ve Benet-Martinez, V. (2007). The geographic distribution of big five personality traits: Patterns and profiles of human self-description across 56 nations. Journal of Cross-Cultural Psychology, 38(2), 173-212.

Servidio, R. (2014). Exploring the effects of demographic factors, Internet usage and personality traits on Internet addiction in a sample of Italian university students. Computers in Human Behavior, 35, 85-92.

Settanni, M., Azucar, D. ve Marengo, D. (2018). Predicting individual characteristics from digital traces on social media: A meta-analysis. Cyberpsychology, Behavior, and Social Networking, 21(4), 217-228.

Sosyalmedya.co (2019, 24 Şubat). İnternet bağımlıları için poliklinik. Erişim adresi: https:// sosyalmedya.co/bakirkoy-internet-bagimliligi-poliklinigi/.

Şentürk, E. (2017). Sosyal medya bağımlılı̆̆ının, depresyon, anksiyete bozukluğu, karışık anksiyete ve depresif bozukluk hastaları ile kontrol grubu arasında karşılaştırılması ve kullanıcıların kişilik özellikleriyle iliş̧kisinin araştırılması (Yayımlanmamış Tıpta Uzmanlık Tezi). Gazi Üniversitesi, Ankara.

Tabachnick, B. G. V. ve Fidell, L. S. (2007). Using multivariate statistics (5. bask1). U.S.A: Pearson Education Inc.

Tan, W-K. ve Yang, C-Y. (2012). Personality trait predictors of usage of internet services. IPEDR, 38, 185-190.

Taş, İ. ve Ayas, T. (2015). Relationship the level of internet addiction with personality traits of high school students. Journal of Human Sciences, 12(2), 150-162.

Tatlılığlu, K. (2014). Üniversite öğrencilerinin Beş Faktör Kişilik Kuramı'na göre kişilik özellikleri alt boyutlarının bazı değişkenlere göre incelenmesi. Tarih Okulu Dergisi (TOD), 7(17), 939-971.

Ünal, T. A. (2015). Sosyal medya bă̆ımlılı̆̆l: Üniversite öğrencileri üzerine bir araştırma (Yayımlanmamış Doktora Tezi). Marmara Üniversitesi, İstanbul.

We Are Social and Hootsuite. (2018, 17 Mart). Global digital snapshot. Erişim adresi: https:// wearesocial-net.s3.amazonaws.com/uk/wp-content/uploads/sites/2/2017/01/Slide007.png

Wolniczak, I., Cáceres-DelAguila, J. A., Palma-Ardiles, G., Arroyo, K. J., Solís-Visscher, R., ParedesYauri, S., ... ve Bernabe-Ortiz, A. (2013). Association between Facebook dependence and poor sleep quality: A study in a sample of undergraduate students in Peru. PLoS ONE, 8(3), e59087. doi:10.1371/journal.pone.0059087

Wooldridge, J. M. (2013), Ekonometriye giriş: Modern yaklaşım, E. Çağlayan (Çev. Ed.), Ankara: Nobel Akademik Yayınc1lık.

$\mathrm{Xu}, \mathrm{H}$. ve Tan, B. C. (2012, Aral1k). Why do I keep checking Facebook: Effects of message characteristics on the formation of social network services addiction. The International Conference on Informations Systems (ICIS), Orlando, FL, USA.

Yakut, S. ve Certel, H. (2016). Öğretmenlerde yalnızlık düzeyinin çeşitli değişkenler açısından incelenmesi. Birey ve Toplum Sosyal Bilimler Dergisi, 6(1), 69-94.

Yıldız, S. ve Sümer, H. H. (2010). Medya ve ahlaki panik. Erciyes Üniversitesi İletişim Fakültesi Dergisi, 1(3), 35-46.

You, S., Kim, E. ve Lee, D. (2017). Virtually real: Exploring avatar identification in game addiction among massively multiplayer online role-playing games (MMORPG) players. Games and Culture, 12(1), 56-71.

Young, K. S. (1998). Caught in the net: How to recognize the signs of internet addiction and a winning strategy for recovery. New York: John Wiley \& Sons.

Young, K. S., Yue, X. D. ve Ying, L. (2011). Prevalence estimates and etiologic models of Internet addiction. K. S. Young ve C. Nabuco de Abreu (Ed.), Internet addiction: A handbook and guide to evaluation and treatment içinde (ss. 1-17). Hoboken, NJ: John Wiley \& Sons. 